SDM-2020 7th International Conference on Sustainable Design and Manufacturing, 09/09/2020 - 11/09/2020, Split, Croatia

Scholz S.G., Howlett R.J., Setchi R. (eds) Sustainable Design and Manufacturing 2020. Smart Innovation, Systems and Technologies, Volume 200, Springer, Singapore. https:// doi.org/10.1007/978-981-15-8131-1_31

\title{
Sustainability assessment of rapid sand mould-making using multi-criteria decision making mapping
}

\author{
Emanuele Pagone ${ }^{[0000-0002-2549-6108]}$, Prateek Saxena ${ }^{[0000-0002-6431-4864]}$, Michail Papani- \\ kolaou $^{[0000-0001-7900-6840]}$, Konstantinos Salonitis ${ }^{[0000-0003-1059-364 X]}$ and Mark Jolly ${ }^{[0000-}$ \\ 0001-6357-3584] \\ Sustainable Manufacturing Systems Centre, School of Aerospace, Transport and Manufactur- \\ ing, Cranfield University, Bedfordshire, MK43 0AL, United Kingdom \\ e.pagonedcranfield.ac.uk
}

\begin{abstract}
Capabilities of Additive Manufacturing (AM) for rapid tooling are well known in recent times. Rapid sand moulds are advantageous over traditional sand moulds in terms of cost, manufacturing time, flexibility, etc. This paper identifies metrics related to mould manufacturing and categorises them into four categories (cost, time, quality and environmental sustainability). A methodology based on the deterministic Technique for Order of Preference by Similarity to Ideal Solution (TOPSIS) multi-criteria decision making algorithm is used to map at high-resolution the influence of such categories on to the decision-making space when comparing AM with conventional sand mould making. Results show that AM is almost always clearly advantageous overall (excluding some very limited corner cases) for the examined case.
\end{abstract}

Keywords: Sand casting, Binder jetting, Mould, Rapid tooling, Decision-making.

\section{$1 \quad$ Introduction}

Sand casting finds its importance in producing near net shape complex geometries. In a traditional sand casting process, hot molten metal is poured in a sand mould and is left to cool down at the room temperature. The molten metal solidifies and the casting is obtained. The pouring process can be manual, semi-automated or fully automated. The flow velocity of molten metal should be controlled to avoid any turbulence and to maintain high casting quality. The sand castings typically have low cooling rates because of the insulation provided by the sand surrounding the molten metal. This is advantageous particularly for shaping hard-to-machine materials [1]. The internal shape of the part is obtained by making use of a core which is placed inside the mould cavity. The cores and patterns are produced by skilled foundrymen [2]; thus, the accuracy of the tooling is dependent upon the skill-set of artisans. The moulds for sand-castings are expendable, i.e. they are temporary and not reusable moulds. One mould can only be used for producing one casting. Consequently, in order to obtain repeatability in castings, moulds should be manufactured with high precision and accuracy. Furthermore, mould manufacturing is not only labour intensive but also time consuming. Gravity 
sand casting process finds its application in casting engine blocks. In the current work, we confine ourselves to the mould manufacturing process for gravity sand casting only.

Additive Manufacturing (AM) commonly referred to as 3D printing, has emerged as a robust and rapid tooling technique in recent years [3]. However, its implementation in sand casting operations is not well explored yet. AM as per NF ISO/ASTM 52900 can be defined as "the process of joining materials to make parts from $3 D$ model data, usually layer upon layer, as opposed to subtractive manufacturing and formative manufacturing methodologies". The expendable mould making process using 3D printing is economical [4] and much faster [5,6] than conventional mould making techniques. Also, the process is suitable for a wide range of materials used for mould making in sand casting process $[5,6]$. For smaller production volumes, pattern making is rather expensive. As the pattern must be removed to create a cavity, this sometimes limit the geometry to be produced from conventional sand casting [7]. Several researchers have highlighted the importance and advantages of rapid sand casting over traditional sand casting [8-10]. However, a robust decision framework has never been implemented in the past to identify the scenarios in which one mould manufacturing method is advantageous over the other, according to the authors' best knowledge.

The work done in this paper identifies critical metrics related to mould sustainability, cost, quality, and time required to produce one mould. The metrics are then categorised into four groups and different scenarios are evaluated. A methodology based on multicriteria decision analysis assigns a pre-determined importance (i.e. weight) to each category of metrics and determines objectively which process is to be preferred in a particular scenario. From a sustainability perspective, such approach also helps to select a cleaner manufacturing process at the same time critically evaluating the overall performance of the rapid sand casting process.

\section{Sand mould manufacturing process}

\subsection{Conventional sand moulds}

In sand casting processes, a sand mould serves as a tool, forming an internal cavity for pouring in and solidifying the molten metal. In parts, such as engine blocks where a complex internal geometry is desired, a secondary tool element known as "core" is used. Cores are fabricated using silica sand and a resin or binder is used to bind and cure the core. Cores are sometimes coated and baked before use.

Mould making is typically a machining process that involves energy consumption. The specific mould making energy $\left(S E C_{\mathrm{m}}\right)$, for the process is $0.16 \mathrm{MJ} / \mathrm{Kg}$ [11]. Similarly, the specific core manufacturing energy $\left(S E C_{\mathrm{c}}\right)$ has been found to be equal to 0.51 $\mathrm{MJ} / \mathrm{Kg}$ [11]. If $w_{\mathrm{m}}$ and $w_{\mathrm{c}}$ represent the weight of sand utilised for mould making and core making respectively, then the total energy consumption $\left(E_{\mathrm{c}}\right)$ in conventional mould and core production can be evaluated from equation 1 .

$$
E_{\mathrm{c}}(\mathrm{MJ})=\left(S E C_{\mathrm{m}} w_{\mathrm{m}}\right)+\left(S E C_{\mathrm{c}} w_{\mathrm{c}}\right)
$$

The $\mathrm{CO}_{2}$ emissions for generating heat using grid electricity (also referred to as carbon intensity) is assumed to be 325 gram $\mathrm{CO}_{2} / \mathrm{KWh}$. More realistic data at any instant 
can be obtained from [12]. The overall $\mathrm{CO}_{2}$ emissions can thus be evaluated from equation 2.

$$
\mathrm{CO}_{2, \mathrm{c}}\left(\mathrm{kg}_{\mathrm{CO}_{2}}\right)=\frac{325}{3600} * E_{\mathrm{c}}(\mathrm{MJ})
$$

\subsection{Rapid sand moulds}

One of the 3D printing technologies utilised for printing sand moulds is binder jetting. The process is capable of fabricating an optimised mould design with identical engineering competence and 33\% lighter than the usual component [10].

The manufacturing process is carried out in seven steps (Fig. 1). A CAD model is first prepared using a standard CAD software and subsequently the model is then fed to the 3D printing machine. A re-coater spreads a layer of sand on the build platform. The inkjet head then sprays the binder droplets forming a layer. The build platform is lowered and the process is repeated to fabricate the next layer. The process continues till the desired part is produced. Unbound sand is then removed using pressurised air or a brush and the finished part is then obtained from the machine. In certain cases, an additional post-curing operation is carried out to enhance the strength of parts. The mould can then be utilised in sand casting operation. Utilisation of 3D printed moulds in energy efficient sand casting processes such as CRIMSON has the potential to produce defect free castings and at the same time reduce the energy consumption of the casting process [13-16]

Energy consumption for mould and core manufacturing depends on the printer specifications. There are several 3D printers available commercially with machine power ranging from $5000 \mathrm{~W}$ to $10300 \mathrm{~W}$. For the current study, a VX500 Voxeljet printer has been considered. The maximum machine power for the printer is $10300 \mathrm{~W}$ with a build (maximum) speed of $3 \cdot 10^{-6} \mathrm{~m}^{3} / \mathrm{s}$. The specific energy consumption $\left(S E C_{\mathrm{m}, \mathrm{c}}\right)$ for manufacturing the sand mould and a core with density $1738 \mathrm{~kg} / \mathrm{m}^{3}$, is $1.08 \mathrm{MJ} / \mathrm{kg}$ [9]. Thus, the total energy consumption $\left(E_{3 \mathrm{D}}\right)$ in 3D printing of sand mould and core can be evaluated from equation 3 . The corresponding $\mathrm{CO}_{2}$ emissions can be obtained from equation 4 (analogous to equation 2).

$$
\begin{aligned}
& E_{3 D}(\mathrm{MJ})=S E C_{m, c}\left(w_{m}+w_{c}\right) \\
& \mathrm{CO}_{2,3 D}\left(\mathrm{~kg}_{\mathrm{CO}_{2}}\right)=\frac{325}{3600} * E_{3 D}(\mathrm{MJ})
\end{aligned}
$$

\section{$3 \quad$ Process selection for mould manufacturing}

The influence of multiple criteria such as environmental sustainability, quality, cost and production time in formulating a decision making approach for optimal process selection is presented in this section. Metrics influencing the sand mould and their effect on the casting quality are considered. The positive or negative impact on the mould making process is identified for each quantity (see Table 1). The effect of increasing the quantity identifies its impact. 


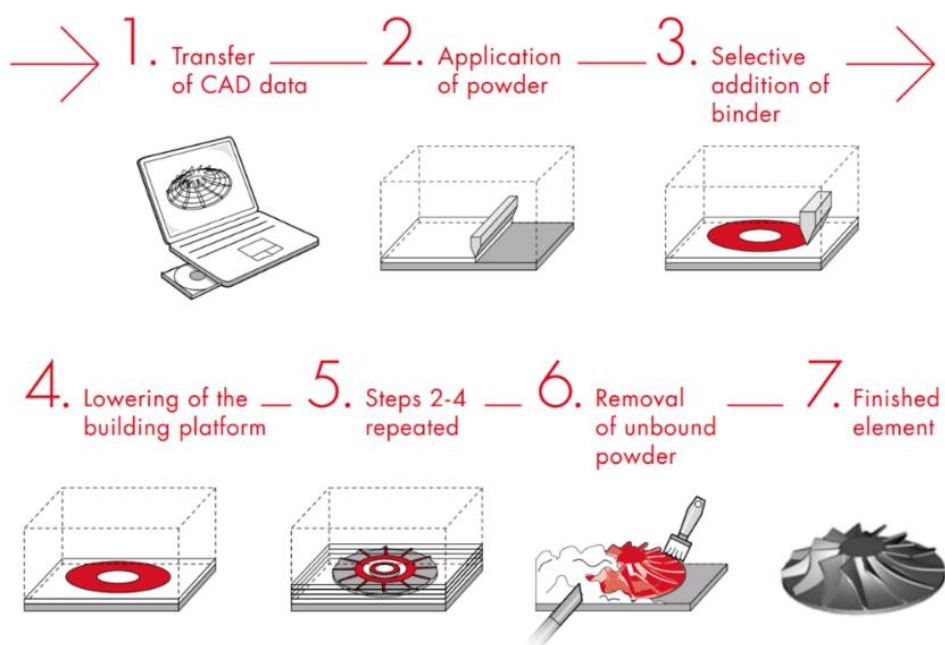

Fig. 1. Fabrication of sand moulds from binder jetting (Image adapted from [17])

Table 1. Selected process metrics for expendable mould manufacturing

\begin{tabular}{lll}
\hline Quantity & Impact & Category \\
\hline Total sand used in mould making & Negative & Environmental sustainability \\
$\left(w_{\mathrm{m}}\right)$ & & Environmental sustainability \\
Total sand used in core making $\left(w_{\mathrm{c}}\right)$ & Negative & Enviran \\
Casting weight $\left(w_{\text {cast }}\right)$ & Negative & Environmental sustainability \\
$\mathrm{CO}_{2}$ emissions $\left(\mathrm{CO}_{2}\right)$ & Negative & Environmental sustainability \\
Total Energy consumption in mould & Negative & Environmental sustainability \\
making $(E)$ & & \\
Tensile strength of mould $\left(\sigma_{\mathrm{t}}\right)$ & Positive & Quality \\
Surface roughness of casting $\left(R_{\mathrm{a}}\right)$ & Negative & Quality \\
Porosity of casting & Negative & Quality \\
Compressive strength of casting $\left(\sigma_{\mathrm{c}}\right)$ & Positive & Quality \\
Hardness of casting $(\mathrm{HV})$ & Positive & Quality \\
Cost of one mould & Negative & Cost \\
Mould making time & Negative & Time \\
\hline
\end{tabular}

\subsection{Environmental sustainability}

Sand casting is one of the most energy-intensive manufacturing processes. Equations (1) - (4) can be used to evaluate the total energy consumption in mould making and the corresponding $\mathrm{CO}_{2}$ emissions. Material data for sand used in fabricating the mould and the core are adapted from Hawaldar and Zhang [8]. The authors fabricated the mould for manufacturing a pump bowl. The core and the mould were manufactured using a VX500 3D printer. The authors reported that the total mass of utilised sand $\left(w_{\mathrm{m}}\right)$ in the conventional and 3D printing processes was equal to $301 \mathrm{~kg}$ and $90 \mathrm{~kg}$ respectively. 
The mass of sand used for manufacturing the core $\left(w_{\mathrm{c}}\right)$ was $7.7 \mathrm{~kg}$ (conventional) and $3.3 \mathrm{~kg}$ (3D printed). The casting mass ( $w_{\text {cast }}$ ) for the two moulds was found to be $34 \mathrm{~kg}$ (conventional) and $23 \mathrm{~kg}$ (3D printed).

Substituting $w_{\mathrm{m}}$ and $w_{\mathrm{c}}$ in equation (1) and (3), the total energy required to manufacture mould using the two mentioned processes is $E_{\mathrm{c}}=52.08 \mathrm{MJ}$ and $E_{3 \mathrm{D}}=110.36 \mathrm{MJ}$ respectively. By substituting the two energy values in equations (2) and (4), the $\mathrm{CO}_{2}$ emissions for the two processes can be evaluated: $\mathrm{CO}_{2, \mathrm{c}}=4.70 \mathrm{kgCO}_{2}$ and $\mathrm{CO}_{2,3 \mathrm{D}}=$ $9.96 \mathrm{kgCO}_{2}$.

\subsection{Quality}

Quality can be evaluated in terms of the quality of the parts produced form the two moulds (conventional and 3D printed sand mould). The strength of the mould itself can be an influencing factor from the mould perspective. Material data for the quality metric have been adapted from Snelling et al. [18]. Sand used for 3D printing is commercially available 3D powder, ViriCast ${ }^{\mathrm{TM}}$, from Viridis 3D. The 3D printed mould allows castings to be produced up to maximum of $1454.4^{\circ} \mathrm{C}$. Five tensile testing specimens were printed and cured at $204.4^{\circ} \mathrm{C}$ for five hours. Standard tensile testing apparatus was used to identify the tensile strength of the $3 \mathrm{D}$ printed dog-bone and compared against the conventional no-bake foundry sand mould. The mean tensile strength $\left(\sigma_{t}\right)$ for the $3 \mathrm{D}$ printed part and the no-bake foundry sand mould were reported to be $0.16 \mathrm{MPa}$ and $0.56 \mathrm{MPa}$ respectively. A356 alloy was then cast using the moulds from the two processes and other characteristics were then identified.

Roughness average $\left(R_{\mathrm{a}}\right)$ for the $3 \mathrm{D}$ printed moulds and no-bake sand moulds was reported to be $13.62 \mu \mathrm{m}$ and $12.17 \mu \mathrm{m}$ respectively. The average density of two castings was found to be identical and equal to $2.61 \mathrm{~g} / \mathrm{cm}^{3}$ and thus density was excluded from the current analysis. Castings produced from 3D printed moulds were more porous compared to those produced from no-bake moulds. Average porosity was found to be $1.13 \%$ and $0.65 \%$ in 3D printed moulds and no-bake moulds respectively. The Vickers Hardness value of two moulds was $92.7 \mathrm{HV}$ (3D printed) and $82.1 \mathrm{HV}$ (no-bake mould). The metal cylinders were also tested for compressive strength and the reported values were $170.8 \mathrm{MPa}$ (3D printed) and $165 \mathrm{MPa}$ (no-bake mould).

\subsection{Cost}

Cost is another important criterion for decision making. It typically involves material, labour, equipment, energy and manufacturing costs. For simplicity all these costs can be referred to as tooling cost. The economics of $3 \mathrm{D}$ printed moulds is dependent on the lead-time $\left(t_{\text {lead }}\right)$ and number of parts [8]. Depending on both factors, 3D printed moulds are capable of saving up to $75 \%$ of the mould manufacturing cost [17]. Table 2 shows the costs in mould manufacturing from the two processes. In the current study, cost for small production volumes (one part) with $t_{\text {lead }}=21$ days is considered. 
Table 2. Tooling cost for mould manufacturing [17]

\begin{tabular}{llll}
\hline & $3 \mathrm{D}$ printed moulds & & Conventional moulds \\
Quantity & $t_{\text {lead }}=5$ days & $t_{\text {lead }}=21$ days & $t_{\text {lead }}=4-6$ weeks \\
\hline 1 & $€ 898$ & $€ 410$ & $€ 3,600$ \\
5 & $€ 3,080$ & $€ 1,428$ & $€ 3,684$ \\
10 & $€ 5,490$ & $€ 2,525$ & $€ 3,789$ \\
50 & $€ 22,275$ & $€ 10,300$ & $€ 4,628$ \\
\hline
\end{tabular}

\subsection{Time}

Time accounts for the total time spent for mould making, core making and fettling time. As 3D printing doesn't require patterns to be produced, time spent in making patterns is excluded from the current study. Fettling time refers to the time spent in removing risers, runners, and feeder head after dismantling the mould by breaking in conventional mould manufacturing. The data for calculating the time spend in two mould making processes have been adapted from [8].

\subsection{Multiple-Criteria Decision Analysis mapping through weighting}

The combination of multiple, conflicting criteria in order to make an objective decision among a number of alternative options, is a sub-discipline of operations research called Multi-Criteria Decision Analysis (MCDA). Several MCDA methods have been developed over the past decades and, among them, the Technique for Order of Preference by Similarity to Ideal Solution (TOPSIS) has attracted significant attention for its ability to correctly compare criteria with different scales and inter-dependencies. Moreover, TOPSIS can take into account of compensatory trade-offs and combine qualitative and quantitative data [19]. TOPSIS applies weights to each criterion (initially normalised) to reflect their importance for the decision maker, then identifies a positive (i.e. best) and negative (i.e. Worst) ideal solution. Finally, a score $s^{-}$is calculated to rank the alternatives considering their closeness to the mentioned ideal solutions. Higher scores imply a better choice [20].

In a previous work by the authors, TOPSIS has been combined with an algorithm capable of automatically mapping the decision-making space at high-resolution [21]. This can be accomplished categorising the criteria (that are considered equally important within each category) and applying an ordinal and combinatorial study of weight distributions to the categories. Four weight distributions laws with self-explanatory names (called "uniform", "halving", "quadratic" and "first two") have been selected to satisfactorily describe the decision-making space (Fig. 2) [21]. 


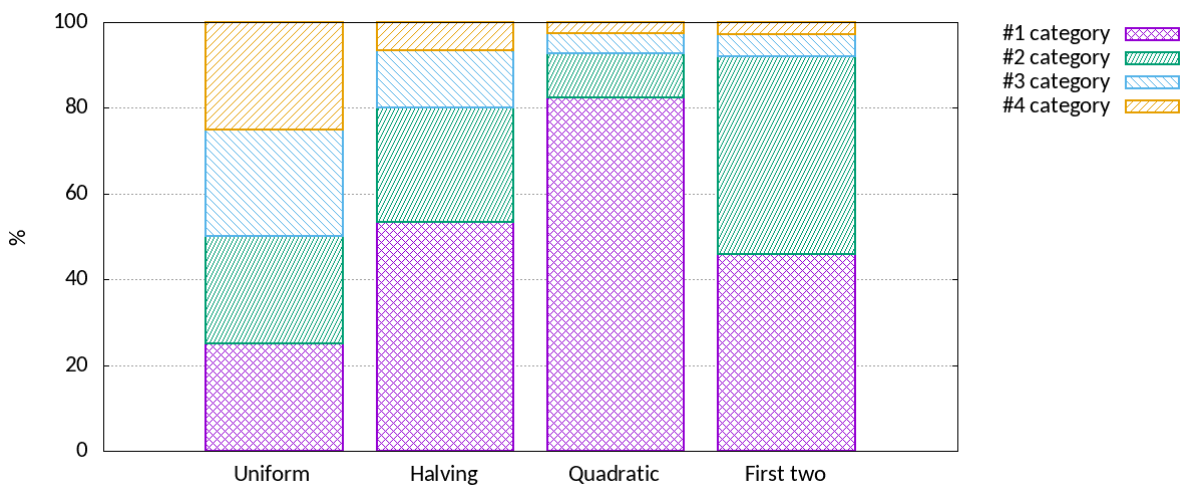

Fig. 2. Weight distribution laws applied to the TOPSIS method for the categories of criteria [21].

Such methodology is used in this study to map the decision-making space of conventional mould-making in comparison with an AM process.

\section{Results and Discussion}

When categories are combined and they are considered equally important for the decision maker, AM clearly appears to be the best choice overall, showing a significant advantage over conventional mould-making (Fig. 3). The maps showing the ordinal combinatorial study with different weight distributions ("halving", "quadratic" and "first two" of Fig. 2) are presented in Fig. 4 identifying each case with the sequence of initial letters for each category (i.e. "e": environmental sustainability, "t": time, "q": quality, "c": cost). The position of the relevant letter in the sequence indicates the ranking of each category to set its weight.

The maps show a clear dominance of the AM option in almost every case. However, it is interesting that conventional mould-making becomes (by a small margin) a better choice when quality is considered to be the most important characteristic according to the decision maker ("quadratic" weight distribution law cases starting with "q" in Fig. 4). Furthermore, another interesting aspect exposed by the high-resolution mapping are a few isolated, corner cases when there is no clear preference between the two options: i.e. when environmental sustainability and quality are the only two important categories ("first two" weight distribution law cases starting with "eq" or "qe" in Fig. 4). For these cases, it would be interesting to amplify the differences between alternatives using the criteria entropy of information [21] to obtain a clearer ranking. 


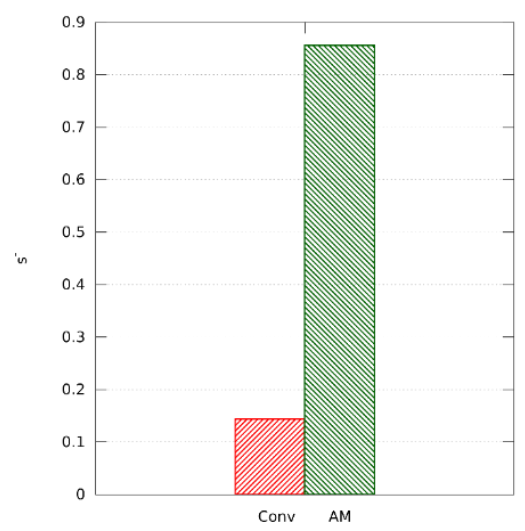

Fig. 3. Overall TOPSIS score $s$ of conventional ("Conv") and Additive Manufacturing ("AM") sand mould-making when all categories are equally important ("uniform" weight distribution law of Fig. 3).

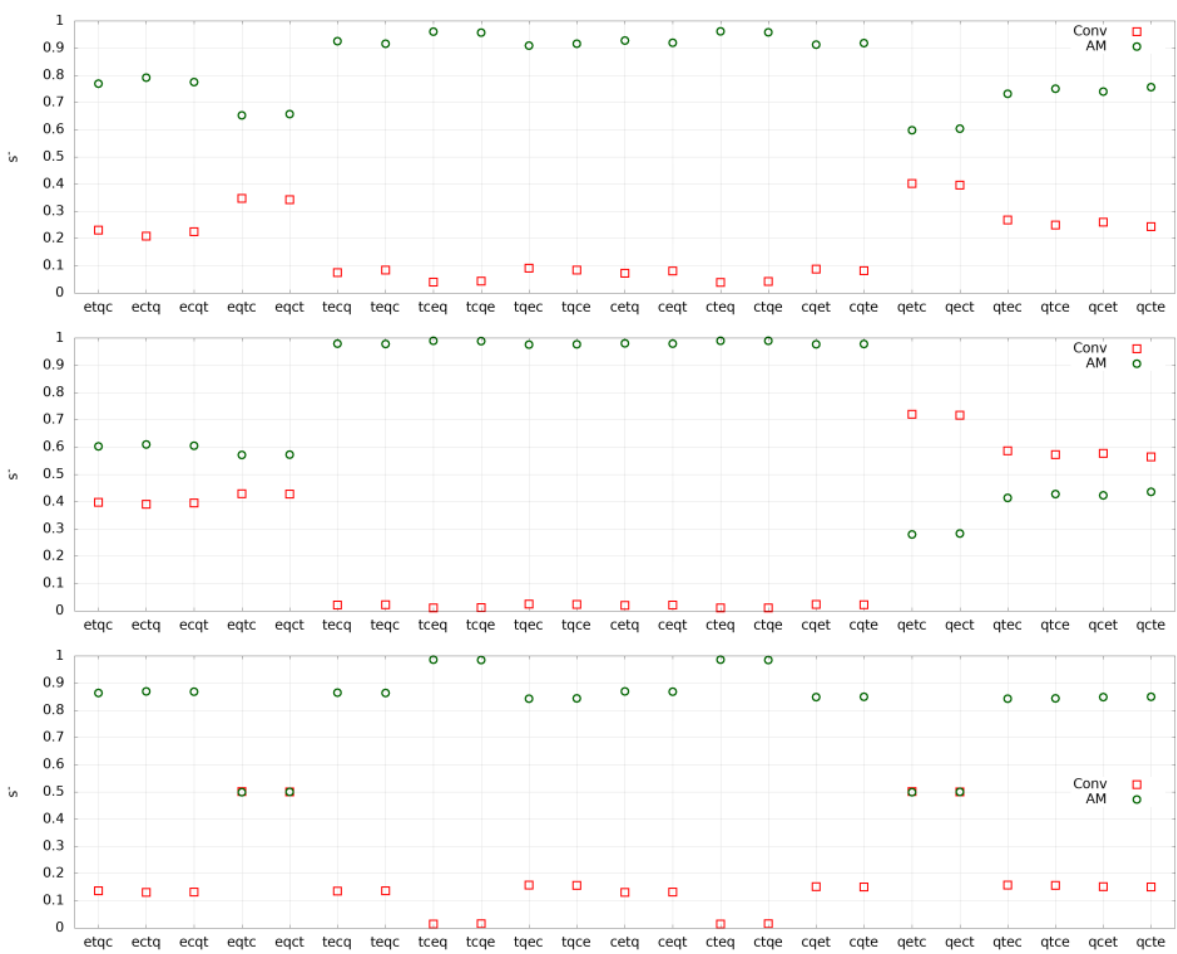

Fig. 4. Overall TOPSIS score $s$ of conventional ("Conv") and Additive Manufacturing ("AM") sand mould-making with "halving" (top), "quadratic" (centre) and "first two" (bottom) weight distributions (as defined in Fig. 3). The importance of categories is represented by the position of its initial letter (i.e. "e": environmental sustainability, "t": time, "q": quality, "c": cost). 


\section{Conclusions}

Sand casting is a well-established shaping process for manufacturing complex geometries. Additive Manufacturing (AM) techniques for rapid tooling have seen a significant development in recent times but their application in printing expendable moulds for sand castings is rather new. The AM printing process is known to be economical and faster than conventional mould making technique. However, there remains a gap in assessing the sustainability of rapid sand casting moulds. This paper establishes a robust sustainability assessment approach to compute key manufacturing quantities (in the categories of cost, time, quality and environmental sustainability) and combines them using a multi-criteria decision analysis tool able to map at high-resolution the decisionmaking space. Results show that in many cases AM is the best choice and identifies a few isolated cases where there is no clear better option between the two (i.e. when both environmental sustainability and quality are the only two most important categories for the decision maker) or when conventional mould making is to be preferred (i.e. when quality is the only major desired characteristic). It can be concluded that, in general, AM mould making is overall more desirable over conventional techniques for producing single mould part. The comparative assessment of medium and large production volumes, including sustainability metrics, can be addressed in future works.

\section{Acknowledgments}

The authors would like to thank the UK Engineering and Physical Sciences Research Council (EPSRC) for their support in the project 'Energy Resilient Manufacturing 2: Small is Beautiful Phase 2 (SIB 2)' (EP/P012272/1).

\section{References}

[1] E. P. DeGarmo, J. T. Black, and R. A. Kohser, Materials and Processes in Manufacturing, 9th editio. New York: Wiley, 2003.

[2] C. K. Chua, S. M. Chou, and T. S. Wong, "A study of the state-of-the-art rapid prototyping technologies," Int. J. Adv. Manuf. Technol., vol. 14, no. 2, pp. 146152, Feb. 1998.

[3] G. N. Levy, R. Schindel, and J. P. Kruth, "Rapid Manufacturing and Rapid toolingwith Layer Manufacturing (LM) Technologies, State of thArt and Future Perspectives," CIRP Ann. - Manuf. Technol., vol. 52, no. 2, pp. 589-609, 2003.

[4] C. Munish, "Rapid casting solutions: a review," Rapid Prototyp. J., vol. 17, no. 5, pp. 328-350, Jan. 2011.

[5] D. Dimitry M., "Advances in three dimensional printing - state of the art and future perspectives," Rapid Prototyp. J., vol. 12, no. 3, pp. 136-147, Jan. 2006.

[6] S. S. Gill and M. Kaplas, "Comparative Study of 3D Printing Technologies for Rapid Casting of Aluminium Alloy," Mater. Manuf. Process., vol. 24, no. 12, pp. 1405-1411, Dec. 2009. 
[7] S. R. Sama, T. Badamo, P. Lynch, and G. Manogharan, "Novel sprue designs in metal casting via 3D sand-printing," Addit. Manuf., vol. 25, pp. 563-578, Jan. 2019.

[8] N. Hawaldar and J. Zhang, "A comparative study of fabrication of sand casting mold using additive manufacturing and conventional process," Int. J. Adv. Manuf. Technol., vol. 97, no. 1, pp. 1037-1045, 2018.

[9] T. Sivarupan, M. Upadhyay, Y. Ali, M. El Mansori, and M. S. Dargusch, "Reduced consumption of materials and hazardous chemicals for energy efficient production of metal parts through 3D printing of sand molds," $J$. Clean. Prod., vol. 224, pp. 411-420, Jul. 2019.

[10] M. Upadhyay, T. Sivarupan, and M. El Mansori, "3D printing for rapid sand casting-A review," J. Manuf. Process., vol. 29, pp. 211-220, Oct. 2017.

[11] G. Design, "CES Edupack Database.” Granta Design, Cambridge, 2016.

[12] ICAX, "Carbon Emissions Calculator." [Online]. Available: https://www.icax.co.uk/Carbon_Emissions_Calculator.html. [Accessed: 01Feb-2020].

[13] M. Papanikolaou, P. Saxena, E. Pagone, K. Salonitis, and M. R. Jolly, "Optimisation of the filling Process in counter-gravity casting," IOP Conf. Ser. Mater. Sci. Eng., 2020.

[14] E. Pagone, K. Salonitis, and M. Jolly, "Energy and material efficiency metrics in foundries," Procedia Manuf., vol. 21, pp. 421-428, Jan. 2018.

[15] K. Salonitis, M. R. Jolly, B. Zeng, and H. Mehrabi, "Improvements in energy consumption and environmental impact by novel single shot melting process for casting," J. Clean. Prod., vol. 137, pp. 1532-1542, Nov. 2016.

[16] P. Saxena, M. Papanikolaou, E. Pagone, K. Salonitis, and M. R. Jolly, "Digital manufacturing for Foundries 4.0," Light Met., 2020.

[17] Voxeljet, "3D printing save up to 75\% in sand casting costs," 2019. [Online]. Available: https://www.voxeljet.com/branchen/cases/3d-druck-spart-bis-zu75-an-kosten-im-sandguss/. [Accessed: 09-Sep-2019].

[18] D. Snelling et al., "The effects of 3D printed molds on metal castings," in Proceedings of the Solid Freeform Fabrication Symposium, 2013, pp. 827-845.

[19] E. Triantaphyllou, B. Shu, S. N. Sanchez, and T. Ray, "Multi-criteria decision making: an operations research approach," Encycl. Electr. Electron. Eng., vol. 15, pp. 175-186, 1998.

[20] C.-L. Hwang, Y.-J. Lai, and T.-Y. Liu, “A new approach for multiple objective decision making," Comput. Oper. Res., vol. 20, no. 8, pp. 889-899, 1993.

[21] E. Pagone, K. Salonitis, and M. Jolly, "Automatically weighted high-resolution mapping of multi-criteria decision analysis for sustainable manufacturing systems," J. Clean. Prod., vol. 257, article no. 120272, Jun. 2020. 


\section{Sustainability assessment of rapid sand} mould-making using multi-criteria decision making mapping

\section{Pagone, Emanuele}

Springer

Pagone E, Saxena P, Papanikolaou M, et al., (2020) Sustainability assessment of rapid sand mould-making using multi-criteria decision making mapping. In: SDM-2020 7th International Conference on Sustainable Design and Manufacturing, 9-11 September 2020, Split, Croatia https://doi.org/10.1007/978-981-15-8131-1_31

Downloaded from Cranfield Library Services E-Repository 